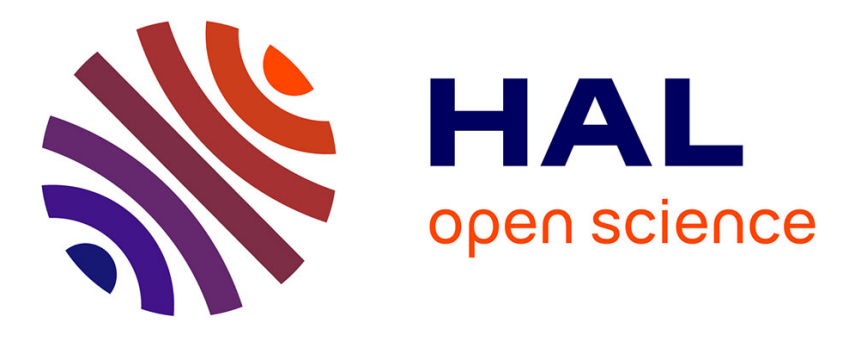

\title{
Spatial analyses of multi-trophic terrestrial vertebrate assemblages in Europe
}

\author{
Joao Braga, Laura Pollock, Ceres Barros, Nuria Galiana Ibañez, José \\ Montoya, Dominique Gravel, Luigi Maiorano, Alessandro Montemaggiori, \\ Gentile Francesco Ficetola, Stéphane Dray, et al.
}

\section{To cite this version:}

Joao Braga, Laura Pollock, Ceres Barros, Nuria Galiana Ibañez, José Montoya, et al.. Spatial analyses of multi-trophic terrestrial vertebrate assemblages in Europe. Global Ecology and Biogeography, 2019, 28 (11), pp.1636-1648. 10.1111/geb.12981 . hal-02399915

\section{HAL Id: hal-02399915 https://hal.science/hal-02399915}

Submitted on 9 Nov 2020

HAL is a multi-disciplinary open access archive for the deposit and dissemination of scientific research documents, whether they are published or not. The documents may come from teaching and research institutions in France or abroad, or from public or private research centers.
L'archive ouverte pluridisciplinaire HAL, est destinée au dépôt et à la diffusion de documents scientifiques de niveau recherche, publiés ou non, émanant des établissements d'enseignement et de recherche français ou étrangers, des laboratoires publics ou privés. 
1 TITLE

2 Spatial analyses of multi-trophic terrestrial vertebrate assemblages in Europe 3

4

5 AUTHORS

6 João Braga ${ }^{1}$, Laura J. Pollock ${ }^{1}$, Ceres Barros ${ }^{1}$, Núria Galiana ${ }^{2}$, José M. Montoya ${ }^{2}$, 7 Dominique Gravel $^{3}$, Luigi Maiorano ${ }^{4}$, Alessandro Montemaggiori ${ }^{4}$, Gentile Francesco $8 \quad$ Ficetola $^{1,5}$, Stéphane Dray $^{6}$, Wilfried Thuiller ${ }^{1}$

9

$10{ }^{1}$ Univ. Grenoble Alpes, Univ. Savoie Mont-Blanc, CNRS, LECA - Laboratoire d'Écologie 11 Alpine, F-38000 Grenoble, France

$12{ }^{2}$ Theoretical and Experimental Ecology Station, CNRS-UPS, 09200 Moulis, France

$13{ }^{3}$ Département de biologie, Université de Sherbrooke, 2500 Boul. De 1'Université, 14 Sherbrooke, Canada.

$15{ }^{4}$ Department of Biology and Biotechnologies "Charles Darwin", Università di Roma "La 16 Sapienza", viale dell’Università 32, 00185, Roma, Italia.

$17{ }^{5}$ Department of Environmental Sciences and Policy, Università degli Studi di Milano. Via 18 Celoria

$19{ }^{6}$ Univ Lyon, Université Claude Bernard Lyon 1, CNRS, Laboratoire de Biométrie et 20 Biologie Evolutive, F-69100, Villeurbanne, France.

22 Corresponding authors - João Braga \& Wilfried Thuiller

23 E-mail address: joao.braga@univ-grenoble-alpes.fr / wilfried.thuiller@univ-grenoble24 alpes.fr 
27 Aim While much has been said on the spatial distribution of taxonomic and phylogenetic diversity of large animals, how this diversity interacts in food webs, and especially how these interactions change across space is largely unknown. Here, we analyzed the spatial distribution of terrestrial vertebrate food webs and asked whether the variation in local food web structure is driven by random processes or by natural and anthropogenic factors.

\section{Location Europe.}

Methods We combined an expert-based food web (1140 species and 76,500 links) of all

European terrestrial vertebrates (mammals, breeding birds, reptiles and amphibians) with their respective spatial distributions. We mapped sixteen different food web metrics representing complexity, chain length, proportion of taxa and diet strategy across Europe and tested whether their distribution reflect the spatial structure of species richness using a null model of food web structure. Then, to avoid multi-collinearity issues, we defined composite descriptors of food web structure that we then related to a set of environmental layers summarizing both natural and anthropogenic influences, and tested their relative importance in explaining the spatial distribution of European terrestrial vertebrate food webs.

Results From the sixteen metrics, six showed a highly structured distribution across Europe and could be summarized along two major axes of variation of food web structure. The first was related to species diversity and proportion of intermediate species and the second was related to connectance and proximity of species within the web. Both descriptors varied with the latitudinal gradient. Mean annual temperature and seasonality was positively correlated with the first axis, while human footprint was positively correlated with the second one.

Main conclusions We provide the first comprehensive spatial description of the vertebrate food web in Europe, and we demonstrate the importance of climate and anthropogenic 50 pressure in shaping the spatial structure of European terrestrial vertebrate food webs. 
52 Key words: ecological network, spatial ecology, multi-trophic food webs, topological 53 properties, tetrapod interactions;

54 


\section{INTRODUCTION}

Documenting large-scale biodiversity distribution and understanding what drives variation between or within different regions of the world has long fascinated naturalists (Wallace, 1876). The recent and ever-increasing rise of large-scale distribution databases (e.g. IUCN, BirdLife, Map Of Life) has led to new comprehensive analyses of biodiversity distribution. Thanks to available data on species traits and phylogenetic relatedness, global and regional patterns of species, traits and phylogenetic diversity are now well documented for terrestrial vertebrates (Jetz \& Fine, 2012; Jetz et al., 2012; Mazel et al., 2014, 2017). on a group of species co-occurring in a certain area or region, which can be subsequently compared with measurements of other areas to identify localities with higher or lower biodiversity (e.g. hotspots vs. coldspots, Mazel et al. 2014). However, species assemblages are not just only the mere sum of species co-occurring in an area, they share a myriad of biotic interactions (e.g. predation, competition, facilitation, etc.) that form a variety of ecological networks through space. While past biogeographic studies have investigated how species or trait diversity vary in space and the underlying role of environment (e.g. Davies et al., 2011; Safi et al., 2011; Mazel et al., 2017), we know little about the spatial distribution of ecological networks (Pellissier et al. 2017).

Food webs are representations of communities' trophic interactions, where each node in the network represents a species and each edge is a directional feeding interaction from a prey to a predator species. Previous studies on food web ecology have been focusing on the trophic relationships between species within discrete communities with the goal of inferring the underlying processes acting upon them, such as relation between species diversity and food web structure, community assembly processes and even robustness of those communities to 
80 (2000) on the latitudinal gradients of aquatic food-web structure, food web ecology has shifted from finding food web structural generalities between communities to search for largescale spatial distribution of ecological networks, such as latitudinal gradients, relation with climate and resource availability (Post, 2002; Kortsch et al., 2015; Montoya \& Galiana, 2017; Pellissier et al., 2017; Poisot et al., 2017; Roslin et al., 2017).

Two hypotheses are commonly proposed to explain the large-scale spatial distribution of food webs. The first hypothesis postulates that species niche breadth increases towards the poles, i.e. species are more diet specialists in the tropics and more generalists as we move away from it due to the environmental stability and the amount of energy influencing niche packing (MacArthur, 1955; Schleuning et al., 2012). This hypothesis has been criticized to be inconsistent across different systems (Cirtwill et al., 2015). The second hypothesis states that low resources at the primary consumers level act as a bottom-up control for species richness and food chain length, while at intermediate level of resource availability, disturbances and ecosystem size drive food chain length (Kaunzinger \& Morin, 1998; Post, 2002). Yet, again such observations are not ubiquitous (Zanden \& Fetzer, 2007). These two hypotheses have, however, never been comprehensively tested over large environmental gradients and for complex (i.e., speciose) food webs.

Here, we take this challenge by building the first comprehensive food web of European vertebrates using a combination of expert knowledge and literature. Then, we mapped the

99 food web structures for all vertebrates' assemblages naturally occurring in Europe, west

100 Russia and Turkey using a uniform spatial grid at $10 \mathrm{~km}$ resolution. On the one hand, instead

101 of focusing on simple food web metrics to test the above-mentioned hypotheses, we extended

102 the analysis to a large set off descriptors such as complexity metrics (species richness, 103 connectance, number of trophic interactions), taxa composition (proportion of basal, 104 intermediate and top predator species), feeding strategy (generality, vulnerability and 
omnivory), and trophic level. We contrast observations to a null model in order to reveal the significant associations between metrics and environmental variables. Most network metrics highly co-vary, either through scaling with the number of species or through connectance

108 (Vermaat et al., 2009; Riede et al., 2010; Baiser et al., 2012; Poisot \& Gravel, 2014), and

109 therefore we decomposed the food web structure into a set of composite descriptors (Pellissier

110 et al., 2017). We investigate how the environment, landscape, and anthropogenic pressures

111 influence the spatial distributions of the different topological network properties.

112 We expected annual temperature and precipitation to be good predictors of food web spatial

113 structure because they are major drivers of species sorting and community assembly over

114 large spatial scales (Riede et al., 2010) (Vázquez \& Stevens, 2004; Ledger et al., 2012).

115 Likewise, highly productive sites also provide more resources for consumers and thereby 116 support higher trophic levels (Wright, 1983; Post, 2002), therefore we also predicted that

117 habitat fragmentation and disturbance to shape European food webs. High levels of

118 fragmentation may reduce the strength of interactions between species or even prevent species 119 from interacting, which may lead to networks with lower link density (Hagen et al., 2012).

\section{MATERIALS AND METHODS}

\section{Study area and species distributions}

123 The study area included Europe (excluding Macaronesia region and Iceland), and the

124 western regions of Turkey and Russia (hereafter referred to as 'Europe'). We extracted 125 species ranges for terrestrial vertebrates naturally occurring within the study area from

126 Maiorano et al., (2013). In total, our analyses focused on 521 bird, 288 mammal, 251 reptile 127 and 104 amphibian species that naturally occur in Europe (see S1 for full species list). Species 128 range data followed a regular grid of $300 \mathrm{~m}$ resolution (WGS84) where Maiorano et al., 129 (2013) classified each cell as zero for unsuitable habitat or one for suitable habitat. All species 
range maps were up-scaled to a 10x10 km equal-size area grid (ETRS89; total of 78875 cells).

131 We considered a species potentially present in a cell (hereafter referred as local assemblage)

132 when at least one $300 \mathrm{~m}$ suitable habitat cell (either as one or two) fell within that same 10x10

$133 \mathrm{~km}$ cell.

\section{European vertebrates metaweb and local food web structure}

136 A trophic metaweb compiles all predator-prey interactions between species for a given

137 regional species pool. Here, we designed the most complete metaweb of European terrestrial

138 vertebrates from expert knowledge, published information and field guides (see references in

139 Supplementary Information). Basically, all obligatory herbivores or insectivores species were

140 assigned to basal species, together with species with fish or any other obligatory diet that does

141 not include other vertebrates. Then, we focused on species feeding upon other vertebrates

142 (including omnivores) and searched for known prey from an exhaustive literature review. We

143 defined a trophic interaction as predation on any life stage of a species (e.g. egg and larval

144 when applicable, juvenile or adult). We considered a trophic interaction potentially feasible

145 between a predator and a prey based on literature review, morphological similarities between

146 potential prey and literature-referenced prey and, in the absence of this information, the diet

147 of predator's sister species. Twelve general diet categories were added to the metaweb, which

148 included detritus, coprophagus, mushrooms, mosses and lichens, algae, fruits, grains, other

149 plant parts, invertebrates, fish, domestic animals and carrion. These categories were used to

150 determine local assemblages and calculate species trophic level (see bellow).

151 The metaweb comprised 70,600 trophic interactions distributed across 1140 species $(60 \%$ of

152 basal species, $33 \%$ of intermediate species and less than one percent by top predator species)

153 and a connectance of 0.05 . Species had on average 61.93 interactions (including prey and

154 predator interactions) and were on average 1.9 interactions away from each other. 
155 We extracted local food webs by intersecting the metaweb with local community 156 composition. In the few cases where a given species was present but having neither available

157 prey given the species distribution data, nor any habitat with its resources for predation to be 158 consummated, we considered the species absent for that particular location (i.e. assuming a 159 false positive in the distribution data). Note that diet categories are ubiquitous across the 160 landscape; therefore species that did prey on them always had resources. As a consequence, 161 basal species have always resources within their extent of occurrence.

162 For each local food web, we calculated sixteen food web properties that belong to four 163 groups: complexity, strategy, taxa composition and trophic level. Complexity metrics include 164 number of species, connectance, clustering coefficient, characteristic path length and link 165 density (average distance between species and average number of interactions per species respectively). Strategy metrics refer to dietary niche properties of species, which include 167 generality (mean number of preys) and vulnerability (mean number of predators), their 168 respective standard deviations, proportion of omnivore species and average trophic similarity

169 between species. Taxa composition metrics quantify the proportion of species along three 170 major trophic levels: basal, intermediate and top level. Trophic level metrics refer to vertical 171 trophic position of species within a food web, which included the mean trophic level and the 172 maximum trophic level present. See Table 1 for individual properties definitions.

174 Climatic, energetic and habitat variables

175 We extracted four climatic variables from the WorldClim database (Hijmans et al., 2005) at $17630^{\circ}$ resolution: annual mean temperature, temperature seasonality (standard deviation of 177 monthly mean temperature), total annual precipitation and coefficient of variation of 178 precipitation. We chose these variables since they correlate with vertebrates species ranges 179 across large spatial scales (Boucher-Lalonde et al., 2014). We approximated the amount of 
resources available to the primary consumers in each pixel with estimates of net primary productivity (grams of carbon per year at 0.25 decimal degrees spatial resolution; Imhoff et al., 2004). We also represented the anthropogenic influence on natural landscape using the human footprint index from the Last of the Wild database (version 2 at $1 \mathrm{~km}$ spatial resolution; WCS \& CIESIN, 2005). We resampled all climatic variables, primary productivity and human footprint data by averaging at the $10 \times 10 \mathrm{~km}$ resolution data used for the species ranges. We also measured habitat diversity using the richness of distinct habitats within a 10 $\mathrm{km}$ cell using the GlobCover habitat classification at $300 \mathrm{~m}$ resolution.

\section{Statistical analyses}

190 Our analyses consisted of three sequential steps. 1) We checked whether the spatial

191 distribution of the local web metrics could result from a purely random process using a null model and only selected the ones that differed from null expectations for subsequent analyses.

2) We reduced the complexity of the retained metrics applying a principal components analysis and selecting the first two axes of variation. 3) We related these two axes of variation to climate, resource availability and human disturbance using generalized additive models (GAMs). Food web structure may vary with the number of species, independently of any others constrains acting upon it (e.g. environment). We thus built a null model to test whether

201 European local food webs and their associated properties could result from a pure random draw from the European species pool, given the observed local species richness. The null hypothesis is that species are randomly distributed in space, independently of the local

204 environment and of their position in the metaweb. We thus sampled local food webs for each 
cell by randomly drawing a number of species from the metaweb corresponding to the observed local richness (from 10 to 300 species). We further applied the constraint that every species needed at least one resource to be included in the food web. For each value of species richness, we repeated the random draw 1000 times and calculated the 16 food web metrics for each repetition in order to obtain a distribution of metrics under the null hypothesis. For each

210 cell, we compared the observed food web metrics to the corresponding null distribution and 211 computed the associated $p$-value. We adjusted $p$-values for multiple comparisons using a false

212 discovery rate method based on Benjamin \& Hochberg (1995) present in the function p.adjust 213 in STATS R package. We retained food web metrics that had $90 \%$ of rejection rate, i.e. $90 \%$ of 214 all local food web metrics were significantly different from ones of random assemblages.

215 Considering that we computed one test per cell (total of 78,875 cells), a food web metric should be significantly different from random expectation in approximately 71,000 cells in order to be kept in our analysis.

\section{How to reduce the redundancy in local food web properties?}

220 Many food web metrics are correlated (Vermaat et al., 2009) either because of their mathematical formulation of because of combinatory constraints (Poisot \& Gravel, 2014). We applied a principal components analysis (PCA) on the six retained variables over the 78,875 cells of Europe (Table 1) to analyze the most insightful axes of variations between these metrics. This allowed us not only to understand how food web metrics co-vary with each other, but also to summarize the food web structure of European assemblages (as a whole) into a set of meaningful axes. We emphasize that the correlation structure among metrics we analyzed is not only driven by the fundamental constraints linking metrics referred above, but also driven by the effect of spatial variation in food web composition. From the PCA, we kept 
web structural composite descriptors. This analysis was performed in R using the ADE4 package (Dray \& Dufour, 2007).

232

\section{How to statistically relate food web structural descriptors to environmental predictors?}

234 We related our food web structural composite descriptors to spatial drivers (climate, 235 energetic and habitat variables) with GAMs. GAMs are more flexible than generalized linear models since we did not have any a priori expectation regarding the shape of the relationships between the response variable and the predictor variables. To avoid fitting over-complex relationships, we constrained the GAMs with a maximum degree of smoothing of 3, which represents a polynomial of degree 2 maximum. All models were fitted using the function gam 240 present in MGCV R package (Wood, 2017).

241 Note that both the environmental variables and the food web topological metrics inevitably

242 show some level of spatial autocorrelation. To account for spatial dependency not explained 243 by the spatial drivers, we first built an autocovariate variable for each of the composite 244 descriptors to estimate how much the response variable for any site reflects the values of the 245 neighboring sites (Dorman et al. 2007; function autocov_dist in SPDEP R package). However, 246 since this autocovariate was unconditional to the environmental variation (i.e. the response 247 variable could show a spatial autocorrelation because the environment is itself 248 autocorrelated), we modelled each autocovariate variable (for each structural composite 249 descriptor) to the set of environmental variables using a bootstrap aggregating model (random 250 forest function in RANDOMFOREST R package; Liaw et al., 2002). We then extracted the 251 residuals of the model and used them as spatial variables independent of the spatial predictors 252 (or at least of the predictor variables used here in the study) in the GAMs. Hereafter, such 253 variables will be referred as spatial residuals variables.

254 We used a "permutation accuracy importance" method (Strobl et al. 2007, 2009) to estimate 
the importance of each predictor variable on the spatial distribution of local food webs metrics. The predictor in test is randomized so that its original association to the response variable is broken. Then, the randomized (through means of permutations) variable and the remaining unchanged predictors are used to predict the response. A "variable importance" score is then measured as the Pearson correlation between the original prediction and the one

260 after permutation of the selected predictor (Strobl et al. 2009). The more the Pearson correlation decreases when the variable is permutated, the more important the variable is. The whole procedure was repeated 1000 times. To ease the interpretation of the results, we reported the average ( 1 - Pearson correlation). Values close to 1 reflected high importance,

264 values close to 0 , no importance.

\section{RESULTS}

\section{Local Food web structure}

Most of the sixteen food web structural metrics showed a strong spatial structure (Figure 1

269 for a selection of six metrics, Fig S1 for all other metrics, and Table 1 for descriptive 270 statistics). Assemblages in northern latitudes (United Kingdom, Denmark and Scandinavian 271 Peninsula) and in mountain ranges (such as Alps and Carpathians) had fewer species, lower trophic levels and higher proportion of basal species than in the rest of Europe. Species in

273 these locations had larger diet breadths (i.e. higher generality) on average. In continental

274 regions, i.e. in central and eastern Europe, food webs tended to be more speciose and with 275 higher trophic levels. Within these food webs, species were more evenly distributed between basal and intermediate species, with top predator species always representing less than $5 \%$ of

277 the community. In southern Europe, along the Mediterranean basin, food webs were the most 278 species rich and had the highest linkage densities and clustering coefficients. In this region, 279 trophic levels were as high as for continental food webs, while, connectance in some areas, 
such as Anatolian region (Turkey) and southeast of Spain, was as high as in near arctic assemblages.

\section{Deviation of local food web structure to random assembly.}

284 Deviations of local food webs to the null expectation varied between the different metrics 285 and across the species richness gradient (Table 1 and Fig. S.2). We observed that only six 286 food web metrics differed at least $90 \%$ of the times from what could be expected from

287 random draws from the metaweb (link density, connectance, proportion of intermediate and 288 omnivore species and characteristic path length). However, for low species richness, most of 289 these metrics do not differ from a random assembly (Figure S.2). The remainder food web 290 properties consistently fell within the random intervals irrespective of species richness (e.g. vulnerability, generality, mean and maximum trophic level; Table 1). In other words, the spatial distribution of these latter metrics could be explained purely by the distribution of species richness.

\section{Composite descriptors of the local realized food webs}

296 Two main axes of variation, explaining approximately $82 \%$ of the total variance, 297 summarized the co-variation of six food web properties (link density, connectance, proportion 298 of intermediate and omnivore species and characteristic path length; Table 2; Fig. 2). The first 299 axis, that we hereafter called richness composite descriptor, explained $52.02 \%$ of structural

300 variation and was related to link density (average number of interactions), proportion of 301 intermediate and omnivore species (Table 2; Fig. 2). This result indicates that food webs with 302 more species have more links per species and higher proportion of intermediate species (i.e.

303 proportion of species having both prey and predators in local food webs).

304 The second descriptor, hereafter named connectance composite descriptor, explained 
$30.08 \%$ of the total variance and was mainly related to food web complexity (through connectance and characteristic path length; Table 2; Fig. 2). Along this descriptor, food web structure showed a negative correlation between characteristic path length and connectance, suggesting that food webs with lower connectance have proportionally longer paths between species.

\section{Environment drivers of local food web descriptors}

312 Environmental drivers explained a significant proportion of the variance of the two

313 composite descriptors (68.9\% of richness, and $38 \%$ for connectance; Table 3$)$. The richness

314 composite descriptor of local, realized food webs was strongly related to temperature

315 variables (mean annual temperature and temperature seasonality). In this model, the temperature variables were positively and linearly related with the richness composite

317 descriptor (Fig. 3a), i.e. sites with high temperatures and high seasonality supported assemblages with more intermediate species and higher link density than ones in with colder

319 climates and low seasonality. While its importance was weaker than temperature variables, net primary productivity correlated positively with the richness composite descriptor, mainly

321 at lower levels of productivity. From lower to intermediate productive areas, we observed a positive relationship with this composite descriptor, i.e. a crescendo in number of species and link density up to intermediate areas; however from intermediate to high productive areas, the

324 contribution of net primary productivity to food web structure was close to zero (Fig. 3a).

325 The human footprint was amongst the most important drivers of variation in the connectance 326 composite descriptor (Table 3). The correlation was positive from low to intermediate values 327 of human footprint (Fig. 3b), and it saturated above intermediate human footprint values.

328 Likewise, for the richness composite descriptor, but not as important, the temperature 329 variables had also a relevant relationship with the connectance composite descriptor (Table 
330 3). Food webs had higher connectance with increasing annual average temperature and 331 seasonality, and species tended to be closer (Fig. 3b). Total annual precipitation correlated

332 positively with the connectance composite descriptor at low to intermediate precipitation, 333 whereas it correlated negatively at larger precipitation levels (Fig. 3b).

334 Spatial residuals variables were important for both summary descriptors of food web

335 structure (Table 3). The importance was particular higher for the connectance composite 336 descriptor than the richness composite descriptor, revealing that there are other spatial 337 processes affecting food web metrics along this axis that were not explained by the variables 338 used here.

\section{DISCUSSION}

341 The variation of food web structure over broad spatial scales is largely unknown in

342 terrestrial systems. Thanks to the compilation of a large dataset comprising pairwise trophic 343 interactions between European tetrapods, their geographical distributions and habitat 344 preferences, we standardized the design of local food webs, allowing for the analysis of food 345 web structure across broad and continuous spatial scales. By doing so, we were able to explore how food web structure varies across Europe.

347 The spatial distribution of European food webs showed that the variation of several food 348 web metrics is driven mostly by the variation in species richness (Table 1). Furthermore, food 349 web structure was not different from random samples from the metaweb at species poor 350 locations (see supplementary figure. S2). In this case, the relationship between these metrics 351 and the number of species implied a threshold number of species that above which food web 352 structure deviates from the null expectation. Note that our assemblages derive from empirical 353 species distributions; therefore food web structural deviations from null expectancies can be 354 attributed to any selective process acting directly on species. 

axes of structural variation, one mainly related to the number of species and another one related to connectance. We had an a priori expectation that species richness and connectance would be two orthogonal axes of variation of food web structure (Martinez, 1994; Riede et al., 2010; Dunne et al., 2013). The study 14 empirical food webs by of Vermaat et al. (2009) showed a similar correlation structure among food web metrics; a similar decomposition was also observed by Baiser et al. (2012) for aquatic food webs spread across North America. Further, the constant connectance hypothesis (Martinez 1992) states that the number of links increases at species square rate if connectance is each species interact with a constant fraction of the network, independently of species richness. Our principal components analysis on European local food web metrics was coherent with these studies, as we observed that connectance tended to be independent of the number of species, while link density increases with species richness. However, a more specific analysis is needed to test both hypotheses. Yet, we speculate as empirical evidence has previously shown, the relationship link-species would lay in between the two hypotheses (Ings et al., 2009).

Climatic gradients, in particular temperature and precipitation, have long been observed as drivers of biodiversity at both local and global scales (Evans et al., 2005). Climate variables may affect food web structure via several means. First, climate acts as an abiotic filter on the assembly of species (Keddy, 1992), which may affect the functional composition of communities and impact food web structure (Lurgi et al., 2012; Blanchard, 2015). Second, it has been suggested that climate variability may directly affect the vertical structure of the

377 food web, where climate stability allows for longer food web chains and narrower diet niches 378 (Menge \& Sutherland, 1987; Vázquez \& Stevens, 2004; Cirtwill et al., 2015). Third, climate may affect food web structural properties, where interannual temperature variability can be 380 negatively correlated with modularity (Welti \& Joern, 2015). Our study documented that 
381 European food web structure, summarized into two descriptors, is related to annual average 382 temperature and its seasonality. The effect of temperature seasonality on food web structure is 383 counter-intuitive, where more climate variability was associated with more species diverse 384 food webs. This result might hide an important structuring effect of landscape structure in 385 Europe. Indeed, most large carnivores, and more generally, top-predators, are mostly present 386 in mountainous areas (the last part of the wild where they were recently re-introduced or 387 protected) where climate variability is the highest. That could explain, in part, this supposedly 388 surprising result.

389 The work from Vermaat et al. (2009) contributed to the understanding of how food web 390 structure co-varied with primary productivity, where trophic level, omnivory, proportion of 391 top species co-varied with primary productivity. Here, we raised a similar question, how resource availability may affect European food web structure in space. Hypotheses relating resource availability and food web structure predict that larger basal resource availability

394 should propagate up the food web, promote species richness and increase food chain length; 395 this relationship should be stronger in low productive environments (Jenkins et al., 1992; 396 Post, 2002). Here, we observed that variation of the average trophic level and proportion of 397 basal species was mostly driven by variation in species richness, as revealed by the 398 comparison to the null model. Therefore such hypothesis linking basal species and trophic 399 level with productivity could not be supported here.

400 Human presence may lead to changes in land-use, habitat fragmentation and pollution, 401 which in turn can negatively affect biodiversity (Barnosky et al., 2011; Cardinale et al., 2012) 402 and food web structure (Evans et al., 2013). Here, we used the human footprint index as a 403 measure of anthropogenic pressure to understand its correlation with vertebrate food web 404 structure. We did find a negative relationship between human footprint and the connectance 405 composite descriptor (Fig. 4). However, we cannot assume this to be a cause-effect 
406 relationship, and it is more likely that it comes from a spatial coincidence between human 407 footprint, species richness and connectance. Climatic conditions and resource availability may 408 affect the spatial distribution of human densities and species diversity alike, which would 409 explain why the two are positively correlated with human population densities (Araújo, 2003).

410 Indeed, despite the weak importance of human footprint on the richness composite descriptor 411 (Table 3), its effect peaked at intermediate levels of human disturbance, where we also found 412 food webs with more species (Fig. 3a). On the other hand, even though the two major 413 complexity food web topological properties, species richness and connectance, were nearly 414 orthogonal in our ordination space (Fig. 2), they were negatively correlated at extreme low 415 values of richness. In general, very small food webs had high values of connectance (note in 416 Fig. 1 that areas with low species richness coincide with areas with high connectance). 417 Therefore, areas with low human footprint also had high connectance composite descriptor, 418 via low values of connectance.

419 The importance of the spatial residuals variable in connectance composite descriptor model 420 suggested the presence of other spatial processes. Since we use species distribution to design 421 European vertebrate assemblages, biogeographical processes, such as barriers to species 422 dispersal or even other biotic factors could lead to spatial similarities and/or dissimilarities in 423 food web structure not explained solely by climate nor resource availability. Further work is 424 needed to include such processes under a beta diversity analysis framework of food web 425 structure (Poisot et al., 2012).

426 A limitation to our design was the even contribution of each prey to the predator's diet and 427 every trophic interaction was constant in space (i.e. if two species interacted in the metaweb, 428 they always interacted across their intercepted spatial range). The former implied that we did 429 not account for biomass or energetic requirements (in contrast, weighted food webs 430 interactions may be defined by biomass relationships) and as consequence we may have 
431 inflated omnivory and connectance. The latter implied no species diet or behavioral 432 adaptability (e.g. prey behavioral changes in function of predator presence or predator diet 433 shift due to presence of competitors; Preisser et al., 2009; Van Dijk et al., 2008; Poisot et al., 434 2012) and as a consequence our webs may have an inflated number of trophic interactions. 435 Further, the environment could influence the occurrence of interactions, which could also 436 influence the spatial structure of food webs. In addition, trophic interactions in our metaweb were defined based not only on empirical studies, but also on by defining a potential array of preys for each predator species and this may inflate generality and vulnerability. We are aware of such issues and more work is necessary to quantify the level of uncertainty of our method, for instance, by using highly resolved empirical food webs and quantify the difference in topological properties obtained with the two methods. Nevertheless, this work is a good example of how biogeography may help comprehend terrestrial food webs spatial patterns.

\section{ACKNOWLEDGEMENTS}

The author JB was supported by the Communautés de Recherche Académique 3 (ARC 3 -

447 Environment) Auvergne Rhône-Alpes, France. JMM is supported by the TULIP Laboratory 448 of Excellence (ANR-10-LABX-41 and 394 ANR-11-IDEX-002-02), and by a Region Midi449 Pyrenees project (CNRS 121090). JB would like to express is gratitude for Julian Renaud for 450 gathering and preparing species distribution to be used in the analysis.

\section{REFERENCES}

453 Araújo, M.B. (2003) The coincidence of people and biodiversity in Europe. Global Ecology and Biogeography, 12, 5-12.

455 Baiser, B., Gotelli, N.J., Buckley, H.L., Miller, T.E. \& Ellison, A.M. (2012) Geographic 
variation in network structure of a nearctic aquatic food web. Global Ecology and Biogeography, 21, 579-591.

458

459

460

461

462

463

464

465

466

467

468

469

470

471

472

473

474

475

476

477

478

479

480

Barnosky, A.D., Matzke, N., Tomiya, S., Wogan, G.O.U., Swartz, B., Quental, T.B., Marshall, C., McGuire, J.L., Lindsey, E.L., Maguire, K.C., Mersey, B. \& Ferrer, E.A. (2011) Has the Earth's sixth mass extinction already arrived? Nature, 471, 51-57.

Blanchard, J.A. (2015) A rewired food web. Nature, 527, 7-8.

Boucher-Lalonde, V., Morin, A. \& Currie, D.J. (2014) A consistent occupancy-climate relationship across birds and mammals of the Americas. Oikos, 123, 1029-1036.

Cardinale, B.J., Duffy, J.E., Gonzalez, A., Hooper, D.U., Perrings, C., Venail, P., Narwani, A., MacE, G.M., Tilman, D., Wardle, D.A., Kinzig, A.P., Daily, G.C., Loreau, M., Grace, J.B., Larigauderie, A., Srivastava, D.S. \& Naeem, S. (2012) Biodiversity loss and its impact on humanity. Nature, 486, 59-67.

Chase, J.M. (2010) Stochastic community asembly causes higher biodiversity in more productive environments. Science, 328, 1388-1389.

Cirtwill, A.R., Stouffer, D.B. \& Romanuk, T.N. (2015) Latitudinal gradients in biotic niche breadth vary across ecosystem types. Proceedings. Biological sciences / The Royal Society, 282, 20151589-.

Currie, D.J. (1991) Energy and large-scale patterns of animal and plant species richness. Am. Nat., 137, 27-49.

Currie, D.J., Mittelbach, G.G., Cornell, H. V., Field, R., Guégan, J.-F., Hawkins, B.A., Kaufman, D.M., Kerr, J.T., Oberdorff, T., O’Brien, E. \& Turner, J.R.G. (2004) Predictions and tests of climate-based hypotheses of broad-scale variation in taxonomic richness. Ecology Letters, 7, 1121-1134.

Davies, T.J., Buckley, L.B., Grenyer, R. \& Gittleman, J.L. (2011) The influence of past and present climate on the biogeography of modern mammal diversity. Philosophical 
Van Dijk, J., Gustavsen, L., Mysterud, A., May, R., Flagstad, Ø., Brøseth, H., Andersen, R., Andersen, R., Steen, H. \& Landa, A. (2008) Diet shift of a facultative scavenger, the wolverine, following recolonization of wolves. Journal of Animal Ecology, 77, 1183 1190.

Dray, S. \& Dufour, A.-B. (2007) The ade4 package: implementing the duality diagram for ecologists. Journal of statistical software, 22, 1-20.

Dunne, J.A., Lafferty, K.D., Dobson, A.P., Hechinger, R.F., Kuris, A.M., Martinez, N.D., McLaughlin, J.P., Mouritsen, K.N., Poulin, R., Reise, K., Stouffer, D.B., Thieltges, D.W., Williams, R.J. \& Zander, C.D. (2013) Parasites Affect Food Web Structure Primarily through Increased Diversity and Complexity. PLoS Biology, 11, e1001579.

Evans, D.M., Pocock, M.J.O. \& Memmott, J. (2013) The robustness of a network of ecological networks to habitat loss. Ecology Letters, 16, 844-852.

Evans, K.L., Warren, P.H. \& Gaston, K.J. (2005) Species-energy relationships at the macroecological scale: a review of the mechanisms. Biological Reviews, 80, 1-25.

Hagen, M., Kissling, W.D., Rasmussen, C., De Aguiar, M.A.M., Brown, L.E., Carstensen, D.W., Alves-Dos-Santos, I., Dupont, Y.L., Edwards, F.K., Genini, J., Guimar??es, P.R., Jenkins, G.B., Jordano, P., Kaiser-Bunbury, C.N., Ledger, M.E., Maia, K.P., Marquitti, F.M.D., Mclaughlin, ??rla, Morellato, L.P.C., O’Gorman, E.J., Tr??jelsgaard, K., Tylianakis, J.M., Vidal, M.M., Woodward, G. \& Olesen, J.M. (2012) Biodiversity, Species Interactions and Ecological Networks in a Fragmented World, Elsevier Ltd.

Hijmans, R.J., Cameron, S.E., Parra, J.L., Jones, P.G. \& Jarvis, A. (2005) Very high resolution interpolated climate surfaces for global land areas. International Journal of Climatology, 25, 1965-1978.

Imhoff, M.L., Bounoua, L., Ricketts, T., Loucks, C., Harriss, R. \& Lawrence, W.T. (2004) 

HANPP Collection: Global Patterns in Net Primary Productivity (NPP).

Ings, T.C., Montoya, J.M., Bascompte, J., Bl??thgen, N., Brown, L., Dormann, C.F., Edwards, F., Figueroa, D., Jacob, U., Jones, J.I., Lauridsen, R.B., Ledger, M.E., Lewis, H.M., Olesen, J.M., Van Veen, F.J.F., Warren, P.H. \& Woodward, G. (2009) Ecological networks - Beyond food webs. Journal of Animal Ecology, 78, 253-269.

Jenkins, B., Kitching, R.L. \& Pimm, S.L. (1992) Productivity, disturbance and food web structure at a local, spatial scale in experimental containers habitats. Oikos, 65, 249-255.

Jetz, W. \& Fine, P.V.A. (2012) Global gradients in vertebrate diversity predicted by historical area-productivity dynamics and contemporary environment. PLoS Biology, 10.

Jetz, W., Thomas, G.H., Joy, J.B., Hartmann, K. \& Mooers, A.O. (2012) The global diversity of birds in space and time. Nature, 491, 444-448.

Kaunzinger, C.M.K. \& Morin, P.J. (1998) Productivity controls food- chain properties in microbial communities. Nature, 395, 495-497.

Keddy, P.A. (1992) Assembly and response rules: two goals for predictive community ecology. Journal of Vegetation Science, 3, 157-164.

Kitching, R. (2000) Food Webs and Container Habitats, Cambridge university press.

Kortsch, S., Primicerio, R., Fossheim, M., Dolgov, A. V \& Aschan, M. (2015) Climate change alters the structure of arctic marine food webs due to poleward shifts of boreal generalists. Proceedings. Biological sciences / The Royal Society, 282, 20151546-.

Ledger, M.E., Brown, L.E., Edwards, F.K., Milner, A.M. \& Woodward, G. (2012) Drought alters the structure and functioning of complex food webs. Nature Climate Change, $\mathbf{3}$, 223-227.

Liaw, A., Wiener, M. \& others (2002) Classification and regression by randomForest. $R$ news,

530 Lurgi, M., Lopez, B.C. \& Montoya, J.M. (2012) Climate change impacts on body size and 
food web structure on mountain ecosystems. Philosophical Transactions of the Royal Society B: Biological Sciences, 367, 3050-3057.

MacArthur, R. (1955) Fluctuations of Animal Populations and a Measure of Community Stability. Ecology, 36, 533-536.

Martinez, N.D. (1994) Scale-dependent constraints on food-web structure. The American Naturalist, 144, 935-953.

Mazel, F., Guilhaumon, F., Mouquet, N., Devictor, V., Gravel, D., Renaud, J., Cianciaruso, M.V., Loyola, R., Diniz-Filho, J.A.F., Mouillot, D. \& Thuiller, W. (2014) Multifaceted diversity-area relationships reveal global hotspots of mammalian species, trait and lineage diversity. Global Ecology and Biogeography, 23, 836-847.

Mazel, F., Wüest, R.O., Gueguen, M., Renaud, J., Ficetola, G.F., Lavergne, S. \& Thuiller, W. (2017) The Geography of Ecological Niche Evolution in Mammals. Current Biology, 16.

Menge, B.A. \& Sutherland, J.P. (1987) Community Regulation: Variation in Disturbance, Competition, and Predation in Relation to Environmental Stress and Recruitment. The

Montoya, J.M. \& Galiana, N. (2017) Integrating Species Interaction Networks and Biogeography. Adaptive Food Webs: Stability and Transitions of Real and Model Ecosystems, p. 289. Cambridge University Press.

Montoya, J.M., Pimm, S.L. \& Solé, R. V. (2006) Ecological networks and their fragility. Nature, 442, 259-264.

Pellissier, L., Albouy, C., Bascompte, J., Farwig, N., Graham, C., Loreau, M., Maglianesi, M.A., Melián, C.J., Pitteloud, C., Roslin, T., Rohr, R., Saavedra, S., Thuiller, W., Woodward, G., Zimmermann, N.E. \& Gravel, D. (2017) Comparing species interaction networks along environmental gradients. Biological Reviews. 
556 Poisot, T., Canard, E., Mouillot, D., Mouquet, N. \& Gravel, D. (2012) The dissimilarity of species interaction networks. Ecology Letters, 15, 1353-1361.

Poisot, T. \& Gravel, D. (2014) When is an ecological network complex? Connectance drives degree distribution and emerging network properties. PeerJ, 2, e251.

Poisot, T., Guéveneux-Julien, C., Fortin, M.J., Gravel, D. \& Legendre, P. (2017) Hosts, parasites and their interactions respond to different climatic variables. Global Ecology and Biogeography, 26, 942-951.

Post, D.M. (2002) The long and short of food-chain length. Trends in Ecology \& Evolution, 17, 269-277.

Preisser, E.L., Bolnick, D.I. \& Benard, M.E. (2005) Scared to death ? The effects of intimidation and consumption in predator-prey Interactions. Ecology, 86, 501-509.

Riede, J.O., Rall, B.C., Banasek-Richter, C., Navarrete, S.A., Wieters, E.A., Emmerson, M.C., Jacob, U. \& Brose, U. (2010) Scaling of Food-Web Properties with Diversity and Complexity Across Ecosystems. Advances in Ecological Research, 42, 139-170.

Roslin, T., Hardwick, B., Novotny, V., Petry, W.K., Andrew, N.R., Asmus, A., Barrio, I.C., Basset, Y., Boesing, A.L., Bonebrake, T.C., Cameron, E.K., Dáttilo, W., Donoso, D.A., Drozd, P., Gray, C.L., Hik, D.S., Hill, S.J., Hopkins, T., Huang, S., Koane, B., LairdHopkins, B., Laukkanen, L., Lewis, O.T., Milne, S., Mwesige, I., Nakamura, A., Nell,

Safi, K., Cianciaruso, M. V., Loyola, R.D., Brito, D., Armour-Marshall, K. \& Diniz-Filho, J.A.F. (2011) Understanding global patterns of mammalian functional and phylogenetic diversity. Philosophical Transactions of the Royal Society B: Biological Sciences, 366, 
Schleuning, M., Fründ, J., Klein, A., Abrahamczyk, S., Alarcón, R., Albrecht, M., Andersson,

Morris, R.J., Sandel, B., Sutherland, W.J., Svenning, J.-C., Tscharntke, T., Watts, S.,

Weiner, C.N., Werner, M., Williams, N.M., Winqvist, C., Dormann, C.F. \& Blüthgen, N. (2012) Specialization of Mutualistic Interaction Networks Decreases toward Tropical Latitudes. Current Biology, 22, 1925-1931.

Vázquez, D.P. \& Stevens, R.D. (2004) The Latitudinal Gradient in Niche Breadth: Concepts and Evidence. The American Naturalist, 164, E1-E19.

Vermaat, J.E., Dunne, J.A. \& Gilbert, A.J. (2009) Major dimensions in food-web structure properties. Ecology, 90, 278-282.

Wallace, A.R. (1876) The Geographical Distribution of Animals: With a Study of the Relations of Living and Extinct Faunas as Elucidating the Past Changes of the Earth's Surface: In Two Volumes, Macmillan and Company, London.

WCS, W.C.S. \& CIESIN, C.U.-C. for I.E.S.I.N. (2005) Last of the Wild Project, Version 2, 2005 (LWP-2): Global Human Footprint Dataset (Geographic).

Welti, E. a. R. \& Joern, A. (2015) Structure of trophic and mutualistic networks across broad environmental gradients. Ecology and Evolution, 5, 326-334. Estimation.

Wright, D.H. (1983) Species-energy theory : an extension of species-area theory. Oikos, 41, 496-506. Oikos, 116, 1378-1388. 